\title{
Link of Oxidative Stress to Pulmonary Functions Contributed by Matrix Metalloproteinase in South Indian Population-An Observational Study
}

\author{
Jothi Marie Feula', Dhanalakshmi Yerrabelli ${ }^{1 * *}$, Gopal Krushna Pal', Sandhiya S²
}

Jothi Marie Feula', Dhanalakshmi $Y^{1, *}$, Gopal Krushna Pal', Sandhiya S2

'Department of Physiology, JPMER, Puducherry, INDIA.

${ }^{2}$ Department of Clinical Pharmacology, JIPMER, Puducherry, INDIA.

\section{*Correspondence}

\section{Dr. Y Dhanalakshmi}

Additional Professor, Department of Physiology, JIPMER, Puducherry, INDIA.

Phone: +91 9444781210

Email: saidhanalakshmi04@yahoo. com

\section{History}

- Submission Date: 21-03-2020;

- Review completed: 27-05-2020;

- Accepted Date: 22-06-2020.

DOI : 10.5530/ijcep.2020.7.2.19

Article Available online

http://www.ijcep.org

\section{Copyright}

(C) 2020 Phcog.Net. This is an openaccess article distributed under the terms of the Creative Commons Attribution 4.0 International license.

\begin{abstract}
Background and Aim: Oxidative stress plays a key role in the etiopathogenesis of several disease conditions and most commonly pulmonary diseases. Pulmonary tissues are susceptible to oxidative stress from ambient air pollution. Serum Malondialdehyde is a sensitive biomarker of oxidative stress. Oxidants also enhance proteinase mediated lung injury. In the current study we have aimed at correlating the serum Malondialdehyde levels with pulmonary functions and serum Matrix mettaloproteinase-9 levels in south Indian population. Methods: This was a cross sectional study conducted among healthy volunteers of age group 18 to 45 years. Pulmonary function tests of the subjects were recorded using computerised spirometry (SPIROLAB III). Serum malondialdehyde levels were estimated using Thiobarbituric acid Reactive Substances assay and serum Matrix metalloproteinase-9 levels were estimated by Enzyme linked Immunosorbent Assay. Results: Significant negative correlation was found between Malondialdehyde and FEV1/FVC ratio and significant positive correlation was found between serum malondialdehyde levels and Matrix metalloproteinase-9 levels. Individual link of Malondialdehyde levels and FEV1/FVC ratio, malondialdehyde levels and Matrix metalloproteinase-9 levels were established by linear regression analysis. Conclusion: Our results state that increased oxidative stress directly affects pulmonary functions and it also increases MMP-9 levels, which again lead to decline in pulmonary functions.
\end{abstract}

Key words: Malondialdehyde, Matrix metalloproteinase-9, Oxidative stress, Pulmonary functions, Free radical injury.

\section{INTRODUCTION}

Oxidative stress plays a key role in the etiopathogenesis of several disease conditions and most commonly pulmonary diseases. ${ }^{[1]}$ Pulmonary tissues are susceptible to oxidative damage as they are more frequently exposed to oxidative stress from ambient air pollution. Imbalance between reactive oxygen species and antioxidants results in oxidative stress. ${ }^{[1]}$ Certain antioxidants are naturally present in blood of healthy individuals and they help in preventing oxidative damage. When there is increased production of reactive oxygen species as in tobacco smoking or exposure to ambient air pollution, the counteracting ability of these naturally occurring antioxidants fail and this lead to oxidative damage of pulmonary tissue. ${ }^{[2]}$ Lipid peroxidation is the most frequently studied effect of oxidative stress. Malondialdehyde (MDA) is a lipid peroxidation end product and it is a sensitive biomarker of oxidative stress. ${ }^{[3]}$ Evidence of oxidative stress as indicated by increased serum Malondialdehyde levels were noted

in patients with Chronic Obstructive Pulmonary Disease (COPD) ${ }^{[4]}$ Yet another mechanism in the pathogenesis of COPD is proteinase - anti proteinase imbalance. Increased proteinase activity is proposed to cause pulmonary extracellular matrix degradation and thereby COPD. There are several proteinases and Matrix Metalloproteinase (MMP) is one such protease. Oxidants were also found to potentiate the effect of proteinases and therefore both oxidants and proteinases interplay in the development of COPD.$^{[5]}$ Though there are evidences regarding the role of the above mentioned etiopathological mechanisms in pulmonary dysfunction, there is paucity in literature demonstrating the relationship between pulmonary functions, oxidative stress and serum proteinase levels in healthy population. So in the current study we have aimed at correlating the serum MDA levels with pulmonary functions and serum MMP-9 levels in south Indian population.

Cite this article: Feula JM, Dhanalakshmi Y, Pal GK, Sandhiya S. Link of Oxidative Stress to Pulmonary Functions Contributed by Matrix Metalloproteinase in South Indian Population-An Observational Study. Int J Clin Exp Physiol. 2020;7(2):77-80. 


\section{MATERIALS AND METHODS}

\section{Study Design}

This cross sectional study was conducted In Department of Physiology, JIPMER, Puducherry. The study was approved by scientific advisory committee and ethics committee of the institute. The sample size was calculated to be 101 by Open Epi software.

\section{Inclusion Criteria}

Healthy volunteers aged 18-45 years, living in any one of the south Indian states (Puducherry, Tamil Nadu, Kerala, Andhra Pradesh and Telangana) for at least three consecutive generations and speaking any one of the south Indian languages (Tamil, Telugu, Malayalam and Kannada) as their mother tongue.

\section{Exclusion Criteria}

Active Smoking, hypertension, diabetes mellitus, alcoholics, endocrinological disorders, acute illness, valvular heart diseases, preexisting respiratory illness.

\section{Procedure}

Subjects were asked to report to pulmonary function testing laboratory, Department of Physiology, at around 9 am, at least $1 \mathrm{hr}$ after a light breakfast, as the maximum forceful expiratory manoeuvre will be restricted when the subject is in full stomach. The procedure was clearly explained to the subjects and informed written consent was obtained. Following this, anthropometric parameters like height, weight and Body Mass Index (BMI) were recorded. Pulmonary function tests of the subject such as forced vital capacity (FVC), forced expiratory volume at $1^{\text {st }}$ second $\left(\mathrm{FEV}_{1}\right), \mathrm{FVC} / \mathrm{FEV}_{1}$, peak expiratory flow rate (PEFR), Forced expiratory flow $_{25}-75 \%\left(\mathrm{FEF}_{25}-75 \%\right)$ were assessed by computerized Spirometry (SPIROLAB III). The test results were interpreted by comparing with the values predicted for height, weight and ethnicity of each individual following American Thoracic Society (ATS) guidelines. ${ }^{[6]}$ Venous blood was collected under sterile aseptic precautions. Serum MDA levels were estimated by Quantitative determination of Thiobarbituric acid Reactive Substances by QuantiChromTM TBARS Assay Kit (DTBA-100). Serum matrix metalloproteinase-9 levels were estimated by RayBio Human MMP-9 Enzyme linked immunosorbent assay (ELISA) kit.

\begin{tabular}{|c|c|c|}
\hline S.No & Parameters & Mean \pm SD / Median (Range) \\
\hline 1 & Age (years) ${ }^{*}$ & $28(38)$ \\
\hline 2 & Body Mass Index $\left(\mathrm{Kg} / \mathrm{m}^{2}\right)^{*}$ & $23.5 \pm 3.8$ \\
\hline 3 & $\operatorname{FVC}(\mathrm{L})^{\#}$ & $2.9 \pm 0.66$ \\
\hline 4 & $\operatorname{FEV} 1(\mathrm{~L})^{*}$ & $3.4 \pm 6.7$ \\
\hline 5 & FEV1/FVC $(\%)^{*}$ & $96(51.8)$ \\
\hline 6 & $\operatorname{PEF}(\mathrm{L} / \mathrm{Sec}) *$ & $6.5(99.36)$ \\
\hline 7 & MMP-9 $(\mathrm{pg} / \mathrm{ml})^{*}$ & $1087(7937)$ \\
\hline 8 & $\operatorname{MDA}(\mu \mathrm{M} / \mathrm{mol})^{*}$ & $2.9(7.4)$ \\
\hline
\end{tabular}

${ }^{*}$ Values are expressed as Median (Range). ${ }^{*}$ Values are expressed as mean \pm SD. FVC - Forced Vital Capacity; FEV - Forced Expiratory Volume at first second; PEF - Peak Expiratory Flow; MMP-9 - Matrix Metalloproteinase-9; MDA Malondialdehyde.

\section{Statistical Analysis of Data}

The results were analyzed using IBM PASW Statistics Version - 19.0 (SPSS version 19.0). The normality of the parameters was tested using Kolmogrov Smirnov test. Normally distributed parameters were expressed in Mean \pm standard deviation (SD). Non normally distributed parameters were expressed as median with Inter Quartile range (IQR). Correlation of serum MDA levels and PFT parameters and correlation of serum MMP-9 levels and MDA levels were done by Spearman's test. P values less than 0.05 were considered statistically significant.

\section{RESULTS}

Out of 100 healthy volunteers recruited for the study, 53 were male and 47 were female. We have recruited individuals of age group 18 to 45 years and the median age of the study population was 28 . Body mass index, FVC, FEV ${ }_{1}$ are normally distributed and expressed as mean with standard deviation. Age, FEV / FVC, PEF, serum MDA and MMP-9 levels are non-normally distributed and expressed in median with range (Table 1).

On correlation of oxidative stress marker MDA with pulmonary function test parameters and serum MMP-9 levels, it was found that MDA levels had significant negative correlation with FEV1/FVC ratio and significant positive correlation with serum MMP-9 levels as shown in Table 2.

Linear regression analysis of MDA with FEV1/FVC, MDA with MMP-9 were done and expressed in Table 3 and 4.

\section{DISCUSSION}

This was a cross sectional study conducted among healthy volunteers of south India. In the current study we have evaluated the correlation between oxidative stress and pulmonary functions and its contribution by MMP-9 in healthy south Indian population. We have recruited individuals between 18 to 45 years of age and the median age of the study population was 28 with range 38 . Since pulmonary functions were reported to be declining with increase in age, we have recruited subjects in this age group. ${ }^{[7]}$

On correlation of serum MDA levels with pulmonary function test parameters, MDA was found to have significant negative correlation with FEV1/FVC ratio. Our results favor the oxidative stress theory of lung injury. ${ }^{[1]}$ Lungs are more prone for exposure to free radicals. Free radicals not only lead to direct lung injury but also cause variety of responses at

Table 2: Correlation of MDA with Pulmonary function test parameters and serum MMP-9 levels.

\begin{tabular}{cccc} 
S.No & PFT parameters & $\begin{array}{c}\text { Correlation } \\
\text { coefficient } \\
\text { (r value) }\end{array}$ & \\
\hline 1 & FVC & -0.179 & 0.075 \\
2 & FEV1 & -0.159 & 0.114 \\
3 & FEV1/FVC & $-0.205^{*}$ & 0.041 \\
4 & PEFR & -.0 .095 & 0.400 \\
5 & FEF25-75 & -.109 & 0.334 \\
6 & MMP-9 & $0.3^{*}$ & 0.007
\end{tabular}

Analyzed by Spearman's test. ${ }^{*} \mathrm{p}$ value less than 0.05 are considered statistically significant, MDA - Malondialdehyde, PFT - Pulmonary function test; FVC - Forced Vital Capacity; FEV $_{1}$ - Forced Expiratory Volume at first second; PEF - Peak Expiratory Flow; FEF 25-75 - Forced expiratory flow ; MMP-9 Matrix metalloproteinase $-9 .{ }^{*} \mathrm{P}$ value less than 0.05 is considered statistically significant. 


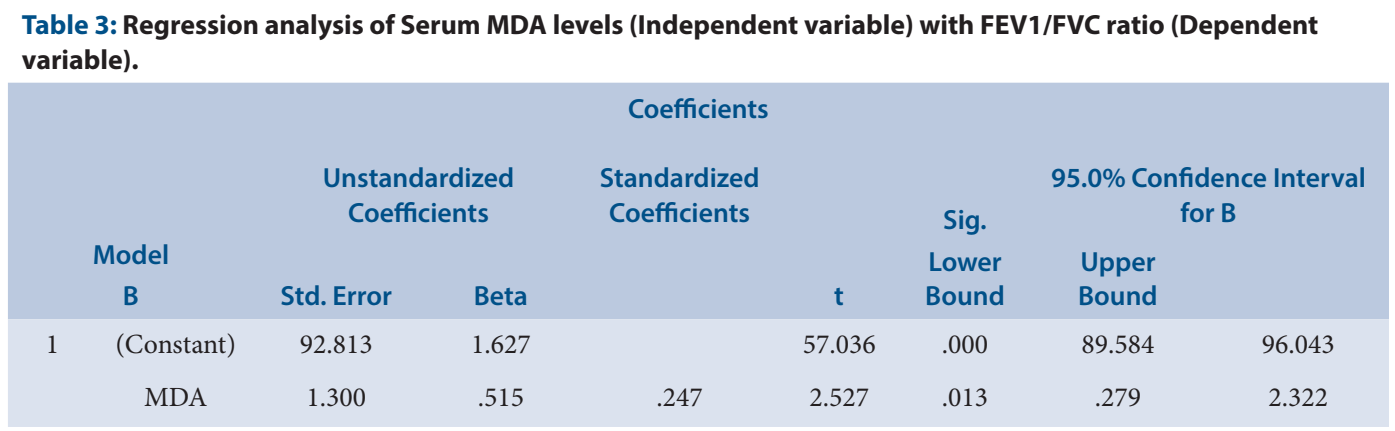

a. Dependent Variable: FEV1FVC

FVC - Forced Vital Capacity; $\mathrm{FEV}_{1}$ - Forced Expiratory Volume at first second, MDA - Malondialdehyde. ${ }^{\star P}$ values less than 0.05 is considered statistically significant. C.I: $95 \%$ confidence interval of unstandardized $\beta$.

Table 4: Regression analysis of Serum MDA levels (Dependent variable) with serum MMP-9 (Independent variable).

\begin{tabular}{|c|c|c|c|c|c|c|c|c|}
\hline \multicolumn{9}{|c|}{ Coefficientsa } \\
\hline & \multirow{2}{*}{$\begin{array}{c}\text { Model } \\
\text { B }\end{array}$} & \multicolumn{2}{|c|}{ Unstandardized Coefficients } & \multirow[t]{2}{*}{$\begin{array}{c}\text { Standardized } \\
\text { Coefficients }\end{array}$} & \multirow[b]{2}{*}{$\mathbf{T}$} & \multirow{2}{*}{$\begin{array}{l}\text { Sig. } \\
\text { Lower } \\
\text { Bound }\end{array}$} & \multicolumn{2}{|c|}{ 95.0\% Confidence Interval for } \\
\hline & & Std. Error & Beta & & & & Upper Bol & \\
\hline \multirow[t]{2}{*}{1} & (Constant) & 2.148 & .305 & & 7.041 & .000 & 1.539 & 2.756 \\
\hline & MMP9 & .000 & .000 & .302 & 2.629 & $.011^{*}$ & .000 & .001 \\
\hline
\end{tabular}

a. Dependent Variable: MDA

MMP-9 - Matrix metalloproteinase -9, MDA - Malondialdehyde. ${ }^{\star} P$ value less than 0.05 is considered statistically significant. CI: $95 \%$ confidence interval of unstandardized $\beta$.

the cellular level. One such response is peroxidation of membrane lipids. MDA is a lipid peroxidation end product and it is an indirect measure of free radical injury and its increased levels results in reduced pulmonary functions.$^{[8]}$ Studies in the past have shown significant increase in serum malondialdehyde levels in COPD patients when compared to healthy controls. Serum malondialdehyde levels were also found to be increasing with increase in severity of the disease, which indicates that the severity of the disease depends on the extent of free radical injury. ${ }^{[9-11]}$ Our study results are also concordant with the previous study conducted by Bartoli et al. Which showed inverse correlation between MDA levels and pulmonary functions. ${ }^{[12]}$

In our study, we also found significant positive correlation between MDA and MMP-9 levels. Oxidative stress enhances the activity of proteinases leading to pulmonary tissue destruction thereby leading to reduced pulmonary functions. The results of our study are similar to those conducted by Koo et al. demonstrating negative correlation between MMP-9 levels and lung functions. ${ }^{[13]}$

Outdoor air pollution is stated to be the major cause of respiratory morbidity. ${ }^{[14]}$ In our current study we have excluded smokers and individuals with pre-existing pulmonary disease and hence the results indicate that oxidative stress has direct effect on the pulmonary functions in healthy individuals. By evaluating the oxidative stress in healthy population, we aim to identify individuals with increased oxidative stress and therefore effective measures like increased intake of antioxidant rich foods can be advised to alleviate the effects of oxidative stress.

MMP-9 having positive correlation with MDA also contributes to reduced pulmonary functions in the study population. MMP-9 is a proteinase, that is released from polymorphonuclear cells in response to inflammation. In addition to oxidative stress, increased activity of MMP-9 can be caused either by inflammation or by overexpression gene polymorphisms. ${ }^{[15]}$
In the current study we have also demonstrated the individual link of FEV1/FVC ratio and MMP-9 levels to MDA by regression analysis and shown in Table 3 and Table 4.

The pathogenesis in the development of obstructive airway diseases include oxidant - anti oxidant balance and proteinase anti proteinase balance. So the limitations of our study is that we have not evaluated the antioxidant status and anti-proteinase levels.

\section{CONCLUSION}

This is a population based study showing the association of oxidative stress biomarker to pulmonary functions. Our results state that increased oxidative stress directly affects pulmonary functions and it also increases MMP-9 levels, which again lead to decline in pulmonary functions.

\section{REFERENCES}

1. Ochs-Balcom HM, Grant BJB, Muti P, Sempos CT, Freudenheim JL, Browne $\mathrm{RW}$, et al. Oxidative Stress and Pulmonary Function in the General Population. Am J Epidemiol. 2005;162):1137-45.

2. Nagaraj KS, Paunipagar P. Study of serum malondialdehyde and Vitamin $C$ in smokers. J Sci Innov Res. 2014;3(6):569-71.

3. Antus B. Oxidative Stress Markers in Sputum. Oxid Med Cell Longev. 2016;1-9.

4. Betsuyaku T, Nishimura M, Takeyabu K, Tanino M, Venge P, Xu S, et al. Evidence for Neutrophil Involvement in the Development of Subclinical Emphysema. Chest. 2000;117(5 Suppl 1):302S-3S.

5. Owen CA. Proteinases and Oxidants as Targets in the Treatment of Chronic Obstructive Pulmonary Disease. 2005;2(4):373-85.

6. SPIROLABIII.pdf [Internet]. [cited 2017 Jun 15]. Available from: https://shop. textalk.se/shop/29011/art85/33054785-9c6c1a-SPIROLABIII.

7. Pruthi N, Multani NK. Influence of Age on Lung Function Tests. J Exerc Sci Physiother. 2012;8(1):1.

8. Bajpai J, Prakash V, Kant S, Verma A, Srivastava A, Bajaj D, et al. Study of oxidative stress biomarkers in chronic obstructive pulmonary disease and their correlation with disease severity in north Indian population cohort. Lung India. $2017 ; 34(4): 324$ 
9. Waseem SMA, Hussain MM, Ahmad Z, Islam N. A Study of Pulmonary Functions and Lipid Peroxidation Biomarker in COPD: Correlation between Malondialdehyde and Lung Functions. Biomed Res. 2012;23:7.

10. Stanojkovic I, Kotur-Stevuljevic J, Milenkovic B, Spasic S, Vujic T, Stefanovic A, et al. Pulmonary function, oxidative stress and inflammatory markers in severe COPD exacerbation. Respir Med. 2011 Oct;105:S31-7.

11. Batra J, Kumar S, Tripathi $Y$, Singh R. Study of pulmonary function test, oxidative stress marker and non-enzymatic antioxidants in Chronic Obstructive Pulmonary Disease. Sch. J. App. Med. Sci., 2016; 4(4D):1371-1374.

12. Bartoli ML, Novelli F, Costa F, Malagrinò L, Melosini L, Bacci E, et al. Malondialdehyde in Exhaled Breath Condensate as a Marker of Oxidative Stress in Different Pulmonary Diseases. Mediators Inflamm. 2011;2011:1-7.
13. Koo HK, Hong Y, Lim MN, Yim JJ, Kim WJ. Relationship between plasma matrix metalloproteinase levels, pulmonary function, bronchodilator response and emphysema severity. Int J Chron Obstruct Pulmon Dis. 2016;11:1129.

14. Ram PM, Dhanalakshmi Y, Feula AJM, Rajaram M, Subitha L, Arvind N, et al. A Comparative Study of Pulmonary Function Test Parameters between the Smokers and Non-Smokers among the Three Wheeler Auto-Rickshaw Drivers in Puducherry Region. Int J Physiol. 2019;7(4):137.

15. Feula JM, Dhanalakshmi Y, Pal GK, Sandhiya S. Frequency distribution of Chronic Obstructive Pulmonary Disease related Matrix Metalloproteinase-9 gene polymorphism in healthy South Indian population. Indian J Basic Appl Med Res J. 2019;8(3):75-80

Cite this article: Feula JM, Dhanalakshmi Y, Pal GK, Sandhiya S. Link of Oxidative Stress to Pulmonary Functions Contributed by Matrix Metalloproteinase in South Indian Population-An Observational Study. Int J Clin Exp Physiol. 2020;7(2):77-80. 